Submitted to Sport, Education and Society April 2007 Revised 25 July 2007

\title{
Coaches, sexual harassment and education
}

by

\section{Kari Fasting $^{1}$ and Celia Brackenridge ${ }^{2}$}

1 Department of Social and Cultural Studies, Norwegian School of Sport Sciences, Oslo, Norway

2 School of Sport and Education, Brunel University, West London, UK

\section{Contact for correspondence:}

Professor Kari Fasting

Department of Social and Cultural Studies

Norwegian School of Sport Sciences

Box 4014

Ulleval Stadion

Oslo 0806

Norway

kari.fasting@nih.no 


\section{ABSTRACT}

Sexual harassment in sport has become an active research field within the past decade yet we know relatively little about the characteristics of the harassing coach. How are harassing coaches characterized by their victims, that is, the athletes themselves? Do they demonstrate specific kinds of behaviours? One purpose of this article is to address these types of questions. Another is to assess the usefulness of general classifications of perpetrators of sexual harassment. This is done by examining whether qualitative data from sexually harassed elite female athletes support the various conceptual frameworks for sexual harassment that are presented. Results from interviews with 19 female elite athletes who were sexually harassed by their coaches produced a sport typology that consists of three main types: 1) The FlirtingCharming Coach, 2) The Seductive Coach and 3) The Authoritarian Coach. These types are discussed in relation to the previous classifications to test the degree of fit. The limitations of monolithic classifications are exposed by this exercise: the data suggest that, rather than being one-type only, sexually harassing coaches select from a repertoire that may include several different harassment scripts. They vary these according to situational conditions. The wider limitation of social science classifications, that their categories are not discrete, also applies here. This need not be a practical limitation, however, if the typologies are used as heuristic devices rather than to determine, for example, specific disciplinary outcomes or treatment regimes. Sexual harassment prevention is often either missing from coach education programmes altogether or subsumed within broader themes such as (gender) equity or diversity management. One of the educational values of typologies is that they focus attention on the range of potential sexually harassing behaviours in ways which might otherwise escape attention. Communication styles, postures, gestures and group management techniques are just some of the elements of coaching that can be improved with an understanding of sexual harassment scripts. It is difficult 
Coaches, sexual harassment and education

to assess whether feminization of the coaching profession would lead to a less harassing environment. But, since this environment is so closely linked to hegemonic masculinity, and what are often described as traditional male values, we hypothesize that a transformation of the coaching culture, and associated re-scripting of coach behaviour, might be easier if more female coaches were involved in sport.

Keywords: Sexual harassment; Female athlete; Classification; Script; Coach education 
Sexual harassment in sport has become an active research field within the past decade (Kirby \& Greaves, 1996; Cense, 1997a and b; Brackenridge, 2001; Leahy et al., 2002; Fasting et al., 2003; Fasting et al., 2004). Research followed the emergence of sexual harassment in sport during the mid-1980s as an issue of concern for both coaches and athletes (Crosset, 1986; Lenskyj, 1992a and b; Brackenridge, 1987, 1991) and as the object of policy development in several industrialised countries such as Canada (CAAWS, 1994), Australia (Australian Sports Commission 1998a, b, c, and d) and the UK (Boocock, 2002). A number of different approaches to sexual harassment research have been taken, from examinations of prevalence (for example, Kirby \& Greaves, 1996; Fasting \& Knorre, 2005), to investigations into athlete perceptions and responses (for example, Volkwein et al., 1997; Hassall et al., 2002; Fasting, Brackenridge \& Walseth, 2002). As yet, however, we know relatively little about the characteristics of the harassing coach. Traditional theories of coaching have often drawn on military metaphors to portray the strength of character and Lombardi-style ("Winning isn't everything, it's the only thing") commitment to toughness that is thought to characterise great coaches. Research on sexual exploitation of female athletes indicates that this kind of coaching style, combined with male coaches' power over the athletes, can in itself be regarded as a risk factor (Brackenridge, 2001). Popular media presentations of harassing coaches, on the other hand, suggest that not only do they have a reputation of being successful coaches but also that they are often regarded as "very nice" people.

Theorisations outside sport often characterise paedophile sexual abuse as a response to lack of success, feelings of resentment and intimacy deficits (Morrison et al., 1994; Hudson \& Ward, 1997). Conversely, many of the accounts of sexual exploitation in sport indicate that perpetrators' feelings of power and control arise from confidence and feelings of superiority (Kirby \& Greaves, 1996; Brackenridge, 1997; Cense, 1997a and b). According to these studies, sexually abusing coaches have good social skills, high visibility, popularity and a high level of 
sexual confidence and assertiveness. But how are harassing coaches characterized by their victims, that is the athletes themselves? Do they demonstrate specific kinds of behaviours? These were the kinds of questions asked in the study presented here.

Sexual harassment is variously defined in the literature but is generally agreed to involve 'unwanted sexual attention'. In sexual abuse, on the other hand, the victim may be either groomed or entrapped, and thus unwittingly consent, or coerced to comply through force. These definitions clearly approach the issue from the victim's point of view but it is also possible to take perpetrator motivation as a starting point. The conceptual and behavioural links between sexual harassment and sexual abuse have been extensively explored, and problematised, elsewhere (Brackenridge, 1997, 2001) so are not revisited here. Nonetheless, it is relevant to this discussion to mention that some sexual abuse researchers, notably those with clinical treatment interests, limit their classifications to those against whom criminal charges have been brought. Many perpetrators of sexual harassment and sexual abuse in sport never reach the criminal justice system because of victims' fears of reprisals, de-selection or not being taken seriously (Brackenridge, 2001). We know little about these non-convicted coach perpetrators, except from interviews with their victims (Brackenridge, 1997; Cense, 1997a and b) and, needless to say, it would be almost impossible to secure consent from such coaches to be interviewed directly since they would first have to agree to be classed as sexual harassers.

In addition to interrogating the interview data, one purpose of this article is to examine the usefulness of general classifications of perpetrators of sexual harassment and to examine whether qualitative data from sexually harassed elite female athletes support various conceptual frameworks for sexual harassment. Implications for re-scripting coach behaviour through education are drawn out in relation to reflexive coaching styles.

\section{The problem of classification}


One approach to enhancing protection against sexual harassment and abuse has been to generate typologies in order to assist predictions of who potential perpetrators might be and how they operate. Classifying or 'profiling' sex offenders in this way is very controversial, as is the whole field of criminal profiling (Jackson \& Bekerian, 1997). Some critics of taxonomies argue that classifying offenders using quasi-medical approaches conveniently obscures the social and moral responsibilities of all men. In a rare study of the offender perspective, for example, Elliott et al. (1995: 592), examined the approach and grooming strategies of 91 convicted sex abusers and concluded "There is no foolproof "profile"" and Hermstad in an interview with Gjelseth (2001) also argues that there is no such thing as a typical abuser.

In sport, rather than criminal detection, the purpose of classifying or profiling harassing coaches is to identify behaviours that lead to offending in order to develop interventions in coach or leadership education, as part of overall prevention work (Brackenridge, 2001; Brackenridge, Bringer \& Bishopp, 2005). Similar efforts have been made in other spheres to identify types of offender or offending strategies or behaviour. In university education, for example, Dziech and Weiner (1984) developed a psychological profile of harassment by men in the academy. They describe the academy as a model of patriarchy in which women are intruders. They sets out five professorial 'seduction scripts' or modi operandi through which female students are harassed by their male professors (p.147). These are: 'The Counselor Helper' who flatters and nurtures the student; 'The Confidant' who draws students into emotional intimacy through developing mutual trust "as friends and equals"; 'The Intellectual Seducer' who flaunts his knowledge to impresses students and coerces them into divulging personal information which they believe is relevant to their studies; 'The Opportunist' who takes advantage of particular locations and situations to perpetrate harassment; and 'The Power Broker' who is coercive about his rights to demand favours from students. Within sport, very few researchers have yet addressed the issue of offender profiling although, arguably, the same power dynamics apply as those found in the 
academy and women may also be deemed to be intruders. Paraphrasing Rosenberg Zalk's analysis of the academy (1990: 85), and applying it to sport, we arrive at the following propositions:

1. The relationship between coach and athlete is based on power. The coach has it and the athlete does not.

2. Theirs is not a collaboration of equals. All the power lies with the coach

3. Knowledge and wisdom - ascribed to good coaches - are power. Athletes often accept uncritically what the coach proposes.

4. The coach's power extends beyond performance issues and over the lives of his athletes.

5. The coach's greatest power lies in the capacity to enhance or diminish athletes' selfesteem.

[Insert Figure 1 about here]

Another conceptual framework for sexual harassment has been proposed by Pryor and Whalen (1997) (Fig.1). Whilst they acknowledge that both personal and situational factors contribute to sexual harassment, they make the assumption that two general psychological functions may be served by such behaviour. These are, first that sexual harassment may arise from an expression of sexual feelings in the perpetrator and, secondly, that it may be an expression of hostility towards an out-group member (p.143). Each of these is further divided into two sub-types. Sexually motivated harassment may involve a) Sexual Exploitation or b) Sexual Attraction/Miscommunication. Hostile Sexual Harassment may be motivated by a) Misogyny or b) what they call 'Homo-anathema' (homophobia).

By this analysis, sexual exploitation is an expression of male power over women, using different sources of power such as organisational, status, physical or situational power: “ $\ldots$ all provide the possibility of one person's will being imposed upon another ... some men may possess a readiness to use power for sexually exploitative ends" (p. 131). Pryor and Whelan 
argue, therefore, that their conception of sexual exploitation involves both sex and power roles and that it is not exclusively associated with either. They assert this in contradiction to the feminist critique of sexual harassment being about power and not about sex (National Council for Research on Women, 1991). This argument underlines the significance of situational factors, cues or triggers in sexual exploitation since, clearly, many men possess power but not all choose to use it for sexually exploitative purposes. Sub-cultural or local social norms are therefore significant features of sexually exploitative practices.

The second type of Sexually Motivated Sexual Harassment is Sexual Attraction/ Miscommunication which, according to Pryor and Whelan arises when the perpetrator misunderstands, misjudges and mishandles an interpersonal encounter: they call these "decoding deficits" (p.136). The harasser's inability to read or respond appropriately to the expectations of the other person leads them, instead, to make "inept overtures" (p. 134). Such scenarios are readily understood through a social constructionist lens. Gutek (1985) suggests that this kind of sexual harassment is more prevalent in sexualised work environments that blur the distinction between private and public life such that, eventually, the sexual harasser cannot distinguish between them. Brackenridge (2001) has suggested that sport is one such environment and that there is high tolerance for sexual bullying and harassment perpetrated by both athlete peers and by authority figures.

Misogyny is the first sub-type of hostility-based sexual harassment in Pryor and Whelan's classification. It is a strong response to women as interlopers, or an out-group, where gender is used as a categorical schema. This is what the sexual harassment researchers Fitzgerald et al. (1997: 10-11) describe as gender harassment. The second sub-type of Hostile Sexual Harassment, Homo-anathema or homophobia, is also an expression of out-group hostility and has been examined in sport contexts for both gay males (Pronger, 1990; Messner, 1992) and for lesbians (Griffin, 1998; Aitchison, 2006). 


\section{Methods}

\section{Participants}

The study reports on semi-structured interviews with 19 elite level Norwegian female athletes, all of whom had experienced sexual harassment in sport by a male coach and who talked about the behavior and the personality of their coach throughout their interviews. The athletes were selected from a survey commissioned by the Norwegian Olympic Committee (Fasting, Brackenridge \& Sundgot-Borgen, 2000). The items relating to sexual harassment in that survey were based on risk factors elicited from an earlier inductive study in the UK study with athletes who had experienced sexual harassment from a coach (Brackenridge, 1997). The overall goal of the Norwegian interviews was to obtain more knowledge about: risk factors, the athletes' reactions to sexual harassment, and the consequences these experiences have had for the athletes. The age of the interviewees ranged from 15 to 33 years, with a mean of 23 years. Two lived alone, seven with their parents, five with a husband/partner, and three with friends. Only one of them had a child. Three were working full time; six had part-time work, and the rest reported that they were students. They represented 12 different sports of which ten were individual sports and two were team sports. On average they had started specializing in their sports at 14 years of age. Some had started as early as ten years of age, and one began her sport at 24 years of age. All of them were among the best in their sports in Norway, and had represented their country in international competitions. Accordingly, the participants spent a significant amount of time in competition and practice. In the periods when they did not compete, more than half of them practiced for 16-20 hours per week (or longer). Eleven of the athletes had competed in the Olympic Games, world championships or world cups, out of which 5 had earned medals. In other words, this interview group of female athletes was a high performance sport group. 


\section{Procedure}

The participants were posted a letter from the chair of the project. In the letter different dates and times for interviews were listed. The participants were asked to telephone in the date and time they could attend to participate in an interview. Permission to undertake the study was provided by the Norwegian Olympic Committee, the Norwegian Data Supervising Bureau, and the Regional Committee for Medical Research Ethics in Oslo. All participants in the study were invited to give permission for a tape recorder to be used during the interview, and all agreed to this. In addition, they all signed a consent form. Written parental consent was obtained from those under the age of 18 years. Pseudonyms were adopted for all respondents. As a safeguard in case any participant might be upset or retraumatized during an interview, the interviewer was able to call on the medical doctor on duty at the Norwegian Olympic Committee training center which was located at the same venue as the interviews. Though a few athletes were upset during their interview, none required contact with a medical doctor.

The interviews were based on the sexual harassment items marked by each respondent during the former survey phase: prompts were used to encourage elaboration. After an introduction about the purpose of the project, in which the applied aspect was stressed and the confidentiality was assured, the athletes were encouraged to talk about setting(s) in which the experience(s) had occurred, what kind of incident they had experienced, the characteristics of the perpetrator, and how they had reacted both in the situation and afterwards. The interviews were conducted in a private office at the national sport university. They lasted between 1 and 2 hours, were transcribed verbatim and analyzed using the WinMax computer software program for text analysis. After transporting the text into WinMax, it was coded at three levels. Level One indicated the type of harasser (e.g., sport manager, coach, sport peer): for each category of harasser, a second level of codes followed the themes used in the interview guidelines, in addition to which some themes (free codes) also emerged from the interviews. An example of a 
Level Two code was 'relationship'. Examples of Level Three codes, which were sub-headings under Level Two, were: 'characteristics of the coach' and 'relationship between the coach and the informant'. After the coding procedure was finished, the data were analyzed according to the principle of "meaning interpretations" (Kvale, 1996). This implies an interpretation that goes beyond what is directly said to work out structures and relations of meanings not immediately apparent in a text. In interpreting the data we also looked for common as well as diverse experiences.

\section{Findings}

The 19 female athletes reported 59 incidents of experiences of sexual harassment from their coaches. Some of these experiences went far back in time, when some of the athletes were 13-15 years of age, but many had happened only recently. The majority of those interviewed had been subjected to "unwanted physical contact" and to "repeated unwanted sexually suggestive glances, jokes, comments," particularly verbal sexist comments about their bodies or part of their bodies and to "ridicule" (Fasting et al., 2002). As an example of unwanted physical contact Kari told us: "We had a coach who all the time was patting us on the bottoms - and many felt it was disgusting ... so then it was just as case of trying to stay 2 meter away from him all the time." As an example of unwanted comments many athletes said they had experienced 'dirty' talk' from their coaches and particular comments about their bodies: "I remember one coach who constantly commented on our bodies, not clothing or private life but appearance of the body" (Lisbeth).

In one part of the interview the athletes talked specifically about the characteristics of the coach, not only their own relationship with him but also their team-mates' relationship to the same coach. Three types emerged from these data which we have labelled as follows: 1) 'The Flirting-Charming Coach', 2) 'The Seductive Coach', and 3) 'The Authoritarian Coach'. The coaches were evenly distributed among these three groups, with six coaches in each. In addition, 
there was one coach who was particularly fond of the smallest and youngest girls. We suspect that he may represent another type which we know exists, that is the paedophile group.

The 'Flirting-Charming Coach' was characterized by always flirting, joking, trying to touch and so on. As an example, Lisbeth said that her coach often tried to 'fight or wrestle with them' for fun and pinched them to check if they had put on weight. She described him in the following way:

It was his way of behaving, his type of humour and style ... he wanted us to look physically like top level athletes, he was very occupied with our appearance, but sometime it was difficult to separate what he was saying to us as athletes and what he was commenting about us as women. I think he mixed the cards.

Another respondent said

I remember a girl on my team whose body had developed early who told me that she was bothered that the coach touched her bottom and breasts. She tried to keep away from him. She dropped out of sport during this time but I don't know if this was because of the coach's behaviour (Irma).

The 'Seductive Coach' went further and was characterized by trying to "hit on everyone". As Ingrid said "I think he had as a goal to get everyone into bed". Bente described her coach as follows:

I know that many of the girls have said that he is a great flirt ... he brought different women with him all the time and was very unfaithful ... he was a real ladies man, and partying as long as possible ... he was always joking sexually.

... and Inger said:

I know that he also tried it on with other girls in the club. I know about at least one other friend who it turned out he had said all the same things to her as to me. He has also written to her, given her flowers and things like that so then it probably isn't as serious as 
he is saying it is. I think it has a lot to do with his personality. He can potentially do this to lots of girls.

According to the athletes, in addition to being powerful and using his power, the ‘Authoritarian Coach' was also characterized by having psychological/psychic problems and often had a degrading, almost negative view of women in general. "With him it is that he has this opinion about women that they should keep silent and do what they are told. That's it", said Kristin. Some athletes were given the feeling that women should not even participate or compete in their sport. Hanne said of her coach:

He has a very strong personality ... very convincing ... very good to have on your side and terrible to have against you. He used power the whole time and is a very charismatic person. I believe that he is more harassing towards girls than boys because boys are stronger and because he has a denigrating attitude towards girls.

The data were also analysed to see if there was any relationship between the type of harassing behaviour experienced by the female athletes overall and these three types of harassing coach behaviour. The main finding was that the coaches in the three groups all used a range of different but overlapping harassing behaviours. However, the athletes who had FlirtingCharming and Seductive Coaches had more often experienced 'unwanted physical contact', such as pinching and fondling, than those who had an Authoritarian Coach. Also, those with FlirtingCharming Coaches had more often than the rest experienced repeated 'unwanted sexual hints' (looks, jokes, comments) about their body, dress, private life and so on. Those with an Authoritarian Coach had been subjected more often to humiliating treatment or ridicule which had undermined their self-respect and even their sport performance. 


\section{Discussion}

In attempting to locate the responses from our interviewees within conceptual frameworks from the literature, we have encountered some interesting opportunities but also several difficulties. The 'Flirting, Charming Coach' appears to align with the Sexual Attraction/Miscommunication sub-type of Sexually Motivated Sexual Harassment. For example, where Irma says "she was bothered that the coach touched her bottom and breasts" he has clearly failed to interpret her annoyance - a "coding deficit" associated with Sexual Attraction/Miscommunication. This offers some useful pointers for coach education that are explored in more detail below.

Our 'Seductive Coach' resembles the Sexually Exploitative sub-type of Sexually Motivated Sexual Harasser in the Pryor and Whelan typology (Fig.1) but could also, in some cases, refer to the Sexual Attraction/Miscommunication sub-type of Sexually Motivated Sexual Harassment. For example, where Inger says of her harasser 'it [the relationship] probably isn't as serious as he is saying it is" she is indicating that she and he have different standpoints (Dougherty, 1999).

Our Authoritarian Coach seems very like Dziech and Weiner's (1984) Power Broker type in the academy and could also be aligned with the Pryor and Whelan Misogyny sub-type of Hostile Sexual Harassment. Reflecting this, for example, Hanne said "He used power the whole time ... he has a denigrating attitude towards women".

Differences in culture can also influence the interpretation of social and situational data. Perhaps most importantly, differences in epistemological commitment also divide those for whom 'pathology is all' from those who believe that offending behaviour is learned. For example, balancing the society/agency influences, Rosenberg Zalk (1990: 82) says: “These men are products of, and mirror, a sexist culture. But ... [that] culture also reflects the psychology of men" (emphasis in the original) whereas Heise, from a cultural feminist perspective, says: "It is 'male conditioning' and not the 'condition of being male' that appears to be the problem" (Heise, 
1997: 242-5). One's standpoint on this matter directly affects judgements about culpability for sexual harassment: is it social learning and pathology or simply social learning that underpins this problem? According to Dougherty (1999), men and women often adopt contrasting standpoints on sexual harassment that lead them to interpret it differently.

Just as with previous attempts to classify sex offenders in general, we find that sexually harassing coaches are also difficult to classify. Indeed, the wider limitation of social science classifications, that their categories are not discrete, also applies here. This need not be a practical limitation, however, if the typologies are used as heuristic devices rather than to determine, for example, specific disciplinary outcomes or treatment regimes. Indeed, one of the educational values of typologies is that they focus attention on the range of potential sexually harassing behaviours in ways which might otherwise escape attention.

As indicated earlier, the three coach groups from our data used a range of different but overlapping harassment behaviours. We suggest, therefore, that the 'types' or 'groups' described above might be more usefully presented as social/sexual scripts rather than as personal features of individual coaches and that each coach has available a repertoire of such scripts, built up through his own socialisation within and outside sport. McKinney (1992: 629) says of scripts that they are

... cognitive representations that provide people with information about the appropriate who, what, where, and when in certain situations ...The content of these scripts may affect how behaviour and individuals in the [coach]-athlete sexual harassment incidents are judged. That is, behaviours not in the script will be seen as less appropriate and more deviant.

It appears coaches may have preferred, dominant or habitual scripts. They select their scripts in different ways according to different circumstances but learn their dominant script(s) through their enculturation into sport as a masculine domain. The hegemonic, misogynistic and 
heterosexist attitudes reflected in some of the athletes' quotations are thus not just reflections of personal views but are generated through the gendered institutional history of sport. This view concurs with that of Hotelling and Zuber (1997) who say that "from a feminist perspective, the occurrence of sexual harassment is fostered by cultural factors that intertwine power, gender and sexuality" (p.106).

As suggested earlier, it is often hypothesized that sexual harassment is motivated not by sexuality but by power, and our findings lend some support to this view. The classic interpretation of power as either 'power over' or 'power as property' is often associated with structural inequalities, because the power exists either within an institution (sport) or within an individual (coach). Structural conceptions of power imply a hierarchy, in that there are the powerful and the powerless. According to this view of power, women - in our case female athletes - can be regarded as (passive) victims who lack the capacity either to resist or to challenge power exerted against them (Brackenridge, 2001). Such a view of power has been criticized, however, particularly because of its lack of attention to agency.

Recent post-structural views of power have focused upon the idea that power is not a fixed property but is negotiated, relational and contingent (Foucault, 1979; Tucker, 1998). Brackenridge (2001) calls this kind of power 'cultural', and states that sexual exploitation can be challenged or resisted through individual agency provided that individuals are empowered to do so. Unfortunately, we are aware of very few initiatives that address athletes' empowerment specifically as a defense against sexual harassment. This does not mean, however, that an individual athlete cannot react to or stop a harassing situation. One of the Flirting-Charming Coaches in this study had the habit of patting or slapping the girls on their rump. This bothered some of the athletes, and Kari told the following story:

... we did talk between us about it - and some were more bothered than others - but most of us knew that he didn't mean it seriously. However, one of my teammates got so angry 
that she finally exploded and said 'if you don't stop doing this I will squeeze your balls next time you do it', and then he became very perplexed and tense and told us that he would never do it again.

We must therefore question how the cultural power relations of sport can be changed or transformed. Is one solution to equalize the number of female and male coaches in sport and/or to improve coach education for both genders? It is to this point that we turn next.

\section{Implications for coach education}

Sexual harassment training for sport coaches is often either missing from coach education programmes altogether or subsumed within broader themes such as (gender) equity or diversity management. When these interviews took place, for example, Norway had no policy for the prevention of sexual harassment, and sexual harassment was not a theme in coach education. In the UK, sports coach UK offer a module entitled Equity in Your Coaching (Sports Coach UK, 2007) but no workshops specifically targeted at preventing sexual harassment in sport. Some coaches, especially those working at elite or 'performance' levels have even suggested that equity and welfare-related training is, at best, an irrelevance or, at worst, an interference with their single-minded pursuit of sporting excellence (Collins, 2006). This contradicts the recommendation for an IOC consensus Statement on Sexual harassment and Abuse in Sport (2007) that says: “All sport organizations should: develop an education and training program on sexual harassment and abuse in their sport(s)" (IOC, 2007: Rec. 4).

As well as being a human rights issue for athletes, however, we suggest that there are also important pedagogic implications of our investigation of sexual harassment. Communication styles, postures, gestures and group management techniques are just some of the elements of coaching that can be improved with an understanding of sexual harassment scripts. The scripts 
outlined in this article also provide plenty of materials for educational scenarios, discussion topics and problem-solving situations that are central to good coach education and that can enhance not only the quality of coach-athlete relations but also the likelihood of athlete adherence (i.e. not dropping out) and eventual performance success. By these methods, the coach's repertoire can be re-scripted to provide a more appropriate, non-harassing range of possibilities. In the USA, the Women's Sports Foundation has promoted guidelines on sexual harassment and sexual relationships between coaches and athletes (Women's Sports Foundation, 2002), and Carole Oglesby, a pioneer of anti-harassment research and practice work in coaching, has conducted just such exercises through workshops. The variety of interpretations of sexual harassment is highlighted by her comment "I've done workshops where, among 30 people in the room, there are ten different perceptions of what sexual harassment is" (Rochman, 2000: 17)

Much more concerted effort needs to be made to confront directly sexual harassment as a feature of the female athlete's experience in sport. Indeed, the results of this enquiry demonstrate the need for more effective coach education and for the mainstreaming of gender issues in all aspects of coaching. Many codes of ethics for coaches contain statements which, had they been followed by the Norwegian coaches, would probably have led to fewer harassing situations. Examples include the Sport and Recreation New Zealand Code of Ethics for Coaches (2007) and the Sports Coach UK Coaches Charter (Child Protection in Sport Unit, 2007).

Interestingly, the emphasis now placed on reflexivity in coaching (Johns \& Johns, 2000; Denison, 2006) is likely to enhance the capability of coaches to self-monitor. It is this skill which Snyder and Cantor argue (1980) decreases the likelihood of miscommunication because it helps more accurate interpretation of interpersonal - including sexual - cues. Whereas Pryor and Whelan describe self-monitoring as a personality construct, we would argue that it is a learned behaviour which therefore has educational potential. 


\section{Limitations}

Several limitations to this empirical work must be recognised. Offender modelling or profiling work has been criticised as being blind to issues of power relations because of its reliance on psychology, or what Burman and Parker call a "celebration of rationality" (1993:7). Indeed, anything informed by traditional psychology is now a target for deconstruction as socially and historically contingent. Jackson and Bekerian (1997) also point to a number of limitations in work on offender profiling. These include lack of unification, diversity of methods and theoretical frameworks and differences between individual profilers.

Secondly, the dates of the interviewees' sexual harassment experiences were not asked for: some might have occurred several years before. Because of this we acknowledge that the data might suffer from memory loss or distortion (Berliner \& Briere, 1999). Thirdly, despite our assurances about confidentiality, respondents might have withheld information for fear of identification of themselves or their coaches. Fourthly, the sexual harassment scripts discussed above emerged from those parts of the interviews where athletes talked about their sexual harassment experiences. We did not originally set out to identify harassing coach profiles or scripts so we lack thick descriptions of them. Finally, it is important to point out that there are also female harassing coaches but, since there are so few female elite coaches, athletes experience this very seldom.

\section{Conclusions}

This article has examined the efficacy of classifications of sexual harassment as conceptual frameworks for coach education about sexual harassment. The limitations of monolithic classifications are exposed by this exercise: instead, the data suggest that sexually harassing 
coaches select from a repertoire that may include several different sexual harassment scripts and that they vary these according to situational conditions. Groups, types and profiles of sexually harassing coaches that have emerged from the literature and from interviews with 19 female elite athletes were discussed in relation to conceptual frameworks for sexual harassment proposed by Pryor and Whelan (1997) and Dziech and Weiner (1984). Whilst we found some similarities between the emergent coach harasser types and these frameworks, there was enough overlap and inconsistency of fit to cause us to reconsider the usefulness of such classifications. Instead, we suggest that various types of sexually harassing behaviour are better conceived of as learned scripts that form part of a repertoire available to any coach. Conceptual frameworks and typologies, including those examined here, are not without benefit, however. They might usefully inform coach education workshops by problematising coach-athlete interactions and by drawing attention to a range of coaching scripts, both harassing and non-harassing.

It is difficult to assess whether feminization of the coaching profession would lead to a less harassing environment. But, since this environment is so closely linked to hegemonic masculinity, and what are often described as traditional male values, we hypothesize that a transformation of the coaching culture, and associated re-scripting of coach behaviour, might be easier if more female coaches were involved in sport.

\section{Acknowledgements}

The research reported in this article was part of a larger project named the Norwegian Women Project, funded by the Norwegian Olympic Committee and Confederation of Sports and the Norwegian School of Sport Sciences. We wish to thank Kristin Walseth for her help with data analysis. 
Coaches, sexual harassment and education

\section{References}

Aitchison, C. C. (Ed.) (2006) Sport and gender identities: masculinities, femininities and sexualities (London, Routledge).

Australian Sports Commission (1998a) Harassment free sport: guidelines for sport administrators (ACT: ASC).

Australian Sports Commission (1998b) Harassment free sport: guidelines for sport organisations (ACT: ASC).

Australian Sports Commission (1998c) Harassment free sport: guidelines for athletes (ACT: ASC).

Australian Sports Commission (1998d) Harassment free sport: guidelines for coaches (ACT: ASC).

Berliner, L. \& Briere, G . (1999) Trauma, memory, and clinical practice, in L. M. Williams \& V. L. Bunyard (Eds.) Trauma and memory pp. 3-18 (Thousand Oaks, CA, Sage).

Boocock, S. (2002) The Child Protection in Sport Unit, Journal of Sexual Aggression, 8(2), 99106.

Brackenridge, C. H. (2001) Spoilsports: understanding and preventing sexual exploitation in sport (London, Routledge). 
Brackenridge, C. H. (1997) “He owned me basically”: Women's experience of sexual abuse in sport, International Review for the Sociology of Sport, 32(2), 115-130.

Brackenridge, C. H. (1987) Ethical problems in women's sport, Coaching Focus, 6, 5-7.

Brackenridge, C. H. (1991) Cross-gender coaching relationships: myth, drama or crisis?, Coaching Focus, 16, 12-14.

Brackenridge, C.H., Bringer, J.D. \& Bishopp, D. (2005) Managing cases of abuse in sport, Child Abuse Review, 14(4), 259-274.

Burman, E. \& Parker I. (Eds.) (1993) Discourse analytic research: repertoires and readings of texts in action (London: Routledge).

CAAWS (Canadian Association for the Advancement of Women and Sport) (1994) Harassment in sport: a guide to policies, procedures and resources (Ottawa, CAAW+S).

Cense, M. (1997a) Rode kaart of carte blanche: risicofactoren voor seksuelle intimidatie en seksueel misbruik in de sport (Arnhem: Netherlands Olympic Committee*Netherlands Sports Federation/TransAct).

Cense, M. (1997b) Red card or carte blanche: risk factors for sexual harassment and sexual abuse in sport. Summary, conclusions and recommendations (Arnhem: Netherlands Olympic Committee*Netherlands Sports Federation/TransAct). 
Coaches, sexual harassment and education

Child Protection in Sport Unit (2007) Coaches Charter,

http://www.thecpsu.org.uk/Scripts/content/Default.asp?Page=ProfCoachesCharter\&MenuPos=L $\underline{\text { eft\&Menu=2200\&Sel=0303 }}\left(\right.$ Retrieved $15^{\text {th }}$ April 2007).

Collins, T. (2006) The experience of elite coaches and child welfare, presentation to a conference 'Safeguarding the Elite Child Athlete' hosted by Brunel University and the NSPCC, London, $4^{\text {th }}$ May.

Crossett,T. (1986) Male coach/female athlete relationships, paper presented at the First International Conference for Sport Sciences, Sole, Norway, $15-16^{\text {th }}$ Nov.

Denison, J. (2006) The way we ran: reimagining research and the self, Journal of Sport and Social Issues, 30(4), 333-339.

Dougherty, D. S. (1999) Dialogue through standpoint: understanding women's and men's standpoints of sexual harassment, Management Communication Quarterly, 12(3), 436-468.

Dziech, B.W. \& Weiner, L. (1984) The lecherous professor. Sexual harassment on campuses (Boston, Beacon Press).

Elliott, M., Browne, K. \& Kilcoyne, J. (1995) Child sexual abuse prevention: what sex offenders tell us, Child Abuse and Neglect, 19(5), 579-594.

Fasting, K., Brackenridge, C. H. \& Sundgot-Borgen, J. (2000) Females, elite sports and sexual harassment (Oslo, the Norwegian Olympic Committee and Confederation of Sports). 
Fasting, K., Brackenridge, C. H. \& Sundgot-Borgen, J. (2003) Experiences of sexual harassment and abuse amongst Norwegian elite female athletes and non-athletes, Research Quarterly for Exercise and Sport, 74(1), 84-97.

Fasting, K., Brackenridge, C. H. \& Sundgot-Borgen, J. (2004) Prevalence of sexual harassment among Norwegian female elite athletes in relation to sport type, International Review for the Sociology of Sport, 39(4), 373-386.

Fasting, K., Brackenridge, C. H. \& Walseth, K. (2002) Consequences of sexual harassment in sport for female athletes, Journal of Sexual Aggression, 8(2), 37-48.

Fasting, K. \& Knorre, N. (2005) Women in sport in the Czech Republic: the experiences of female athletes (Oslo and Prague, Norwegian School of Sport Sciences and Czech Olympic Committee).

Fitzgerald, L. F., Swan, S. \& Magley, V. J. (1997) But was it really sexual harassment? Legal, behavioral, and psychological deifinitions of workplace vgictimzation of women, in W. Donohue (Ed.) Sexual harassment: theory, research and treatment pp. 5-28 (London, Allyn and Bacon).

Foucault, M. (1979) Discipline and punish: the birth of the prison (New York, Vintage Books).

Gjelseth, G. (2001) Den typiske overgriper fines ikke, Forelde and Barn, 25(1), 53-55. 
Coaches, sexual harassment and education

Griffin, P. (1998) Strong women, deep closets: lesbians and homophobia in sport (Champaign.

IL, Human Kinetics).

Gutek, B. (1985) Sex and the workplace (San-Franciso, CA, Jossey-Bass).

Hassall, C., Johnston, L.H., Bringer, J.D. \& Brackenridge, C.H. (2002) Attitudes towards sexual harassment: Coach and athlete perceptions of ambiguous behaviours, Journal of Sport Pedagogy, $8(2), 1-21$.

Heise, L. L. (1997) Violence, sexuality and women's lives, in: R. Lancaster \& M. di Leonardo (Eds) The gender and sexuality reader: culture, history, political economy (London, Routledge).

Hotelling, K. \& Zuber, B. A. (1997) Feminist issues in sexual harassment, in W. Donohue (Ed.) Sexual harassment: theory, research and treatment Ch.6, pp. 99-111 (London, Allyn and Bacon).

Hudson, S. M. \& Ward, T. (1997) Intimacy, loneliness and attachment style in sexual offenders, Journal of Interpersonal Violence, 12, 323-339.

International Olympic Committee (2007) Consensus statement: sexual harassment and abuse in sport, IOC Medical Commission Expert Panel, http://www.olympic.org/uk/organisation/commissions/medical/full_story_uk.asp?id=2064 (retrieved $16^{\text {th }}$ Apr 2007).

Jackson, J. L. \& Bekerian, D.A. (1997) Offender profiling: theory, research and practice (New York, Wiley). 
Johns, D. \& Johns, J. (2000) Surveillance, subjectivities and technologies of power: an analysis of the discursive practice of high performance sport, International Review for the Sociology of Sport, 35(2), 219-234.

Kirby, S. and Greaves, L. (1996) Foul play: Sexual abuse and harassment in sport, paper presented to the Pre-Olympic Scientific Congress, Dallas, USA, $11-14^{\text {th }}$ July.

Kvale, S. (1996) Interviews - an introduction to qualitative research interviewing (Thousand Oaks, CA, Sage).

Leahy, T., Pretty, G. \& Tenenbaum, G. (2002) Prevalence of sexual abuse in organised competitive sport in Australia, Journal of Sexual Aggression, 8(2), 16-36.

Lenskyj, H. (1992a) Sexual harassment: female athletes' experiences and coaches' responsibilities, Sport Science Periodical on Research and Technology in Sport, Coaching Association of Canada, 12, 6, Special Topics B-1.

Lenskyj, H. (1992b) Unsafe at home base: Women's experiences of sexual harassment in university sport and physical education, Women in Sport and Physical Activity Journal, 1(1), 1934.

McKinney, K. (1992) Contrapower sexual harassment: the effects of student sex and type of behaviour on faculty perceptions, Sex Roles, 27(11/12), 627-643. 
Messner, M. (1992) Power at play: sports and the problem of masculinity (Boston, Beacon press).

Morrison, T., Erooga, M. \& Beckett, R. (Eds) (1994) Sexual offending against children: assessment and treatment of male abusers (London, Routledge).

National Council for Research on Women (1991) Sexual harassment: research and resources (New York, NCRW).

Pronger, B. (1990) The arena of masculinity: sports, homosexuality, and the meaning of sex (London, GMP Publishers Ltd.).

Pryor, J. B. \& Whalen, N. J. (1997) A typology of sexual harassment of sexual harassment: characteristics of harassers and the social circumstances under which sexual harassment occurs, in: W. Donohue (Ed) Sexual harassment: theory, research and treatment pp. 129-151 (London, Allyn and Bacon).

Rochman, S. (2000) 'Crossing boundaries', Athletic Management, Feb/Mar, 12(2), 20-27.

Rosenberg Zalk, S. (1990) Men in the academy: A psychological profile of harassment, in: M. A. Paludi (Ed) Ivory power: sexual harassment on campus, pp. 142-175 (Albany, NY, State University of New York Press).

Snyder, M. \& Cantor, N. (1980) Thinking about ourselves and others: self-monitoring and social knowledge, Journal of Personality and Social Psychology, 39, 222-234. 
Coaches, sexual harassment and education

Sport and Recreation New Zealand (2007) Code of ethics for coaches

http://www.sparc.org.nz/filedownload?id=7d68ae1f-8bc2-4add-bf9d-0c580d5455c4 (retrieved $15^{\text {th }}$ April 2007).

Sports Coach UK (2007) Workshop outcomes,

http://www.sportscoachuk.org/Events+and+Courses/sports+coach+UK+Workshops/scUK (retrieved $15^{\text {th }}$ April 2007).

Tucker, K. H. (1998) Anthony Giddens and modern social theory (London: Sage).

Volkwein, K., Schnell, F., Sherwood, D. and Livezey, A. (1997) Sexual harassment in sport: perceptions and experiences of American female student-athletes, International Review for the Sociology of Sport, 23 (3), 283-295.

Women's Sports Foundation (2002) Sexual harassment and sexual relationships between coaches and athletes: The Foundation perspective, $14^{\text {th }}$ August http://www.womensportsfoundaiton.org/cgi-bin/iowa/issues/coach/article/html (retrieved 7th November 2002). 
Coaches, sexual harassment and education

Fig. 1 Conceptual framework for sexual harassment (after Pryor and Whalen, 1997: 143) 


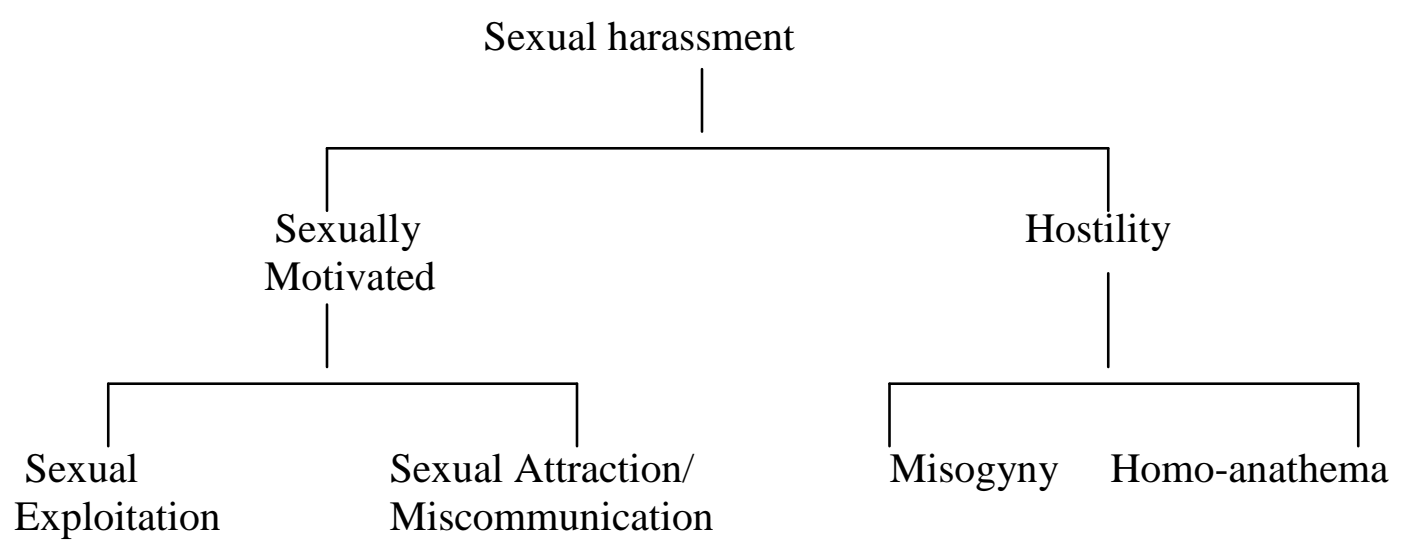

